\title{
Koncepcja efektów mnożnikowych w wyznaczaniu wpływu przedsiębiorstw na otoczenie społeczno-gospodarcze
}

Powstanie lub rozwój działalności gospodarczej na danym obszarze prowadzić może do wzrostu dochodów i zatrudnienia w wielu innych przedsiębiorstwach, a także do zwiększenia wpływów podatkowych władz lokalnych. Wzrost ten określany jest mianem efektów mnożnikowych, a ich wielkość pozwala ocenić wpływ działalności przedsiębiorstwa na funkcjonowanie firm $w$ jego otoczeniu.

Najczęściej rozpatruje się dwa podstawowe rodzaje efektów mnożnikowych: efekty zaopatrzeniowe i efekty dochodowe. Te pierwsze wynikają z dodatkowego popytu tworzonego przez nowo powstałe lub rozwijające się przedsiębiorstwa, umożliwiającego wzrost firm będących dla nich dostawcami dóbr i usług. Efekty dochodowe są skutkiem zwiększenia się siły nabywczej ludności poprzez wynagrodzenia pracowników, a tym samym przyczyniają się do rozwoju firm zaspokajających potrzeby konsumpcyjne. W ten sposób rozwój jednych firm za pośrednictwem dodatkowego zapotrzebowania na produkty i usługi ,pomnaża się” w postaci rozwoju innych podmiotów gospodarczych. Podmioty te z kolei same także stwarzają większy popyt, wywołując kolejne cykle efektów mnożnikowych (ryc. 1).

Ponieważ firmy i ich pracownicy płacą podatki, rozwój firm zwiększa także dochody budżetu państwa oraz gmin i powiatów. Dotyczy to zarówno podatków od dochodów osób fizycznych i prawnych (PIT, CIT), jak i podatków od nieruchomości i środków transportu, które to z kolei wpływają wyłącznie do budżetów gmin. Odprowadzane podatki mogą stać się z kolei źródłem inwestycji finansowanych z budżetu centralnego oraz prowadzonych na różnych szczeblach administracji samorządowej.

Wielkość poszczególnych rodzajów efektów mnożnikowych jest ponadto silnie zróżnicowana w przestrzeni społeczno-gospodarczej. Wynika to z różnorodności powiązań firm z ich otoczeniem lokalnym i regionalnym. O ile skutki dochodowych efektów mnożnikowych koncentrują się głównie w otoczeniu lokalnym, to powiązania zaopatrzeniowe w zdecydowanej większości wykraczają poza ten obszar. Siłę powiązań przedsiębiorstwa z otoczeniem zewnętrznym nazywamy jego zakorzenieniem (termin pochodzący od angielskiego embeddedness).

$\mathrm{Na}$ temat oddziaływania firm na otoczenie od lat pięćdziesiątych XX w. powstało wiele opracowań. Większość z nich opiera się na teorii bazy ekonomicznej G. Myrdala (1957) oraz modelach input-output opracowanych przez noblistę W. Leontiefa. Rozwój pierwszych regionalnych modeli ekonomicznych przeprowadził Ch.M. Tiebout (1957). Później powstało wiele prac zajmujących się estymacją efektów mnożnikowych w ramach różnych regio- 


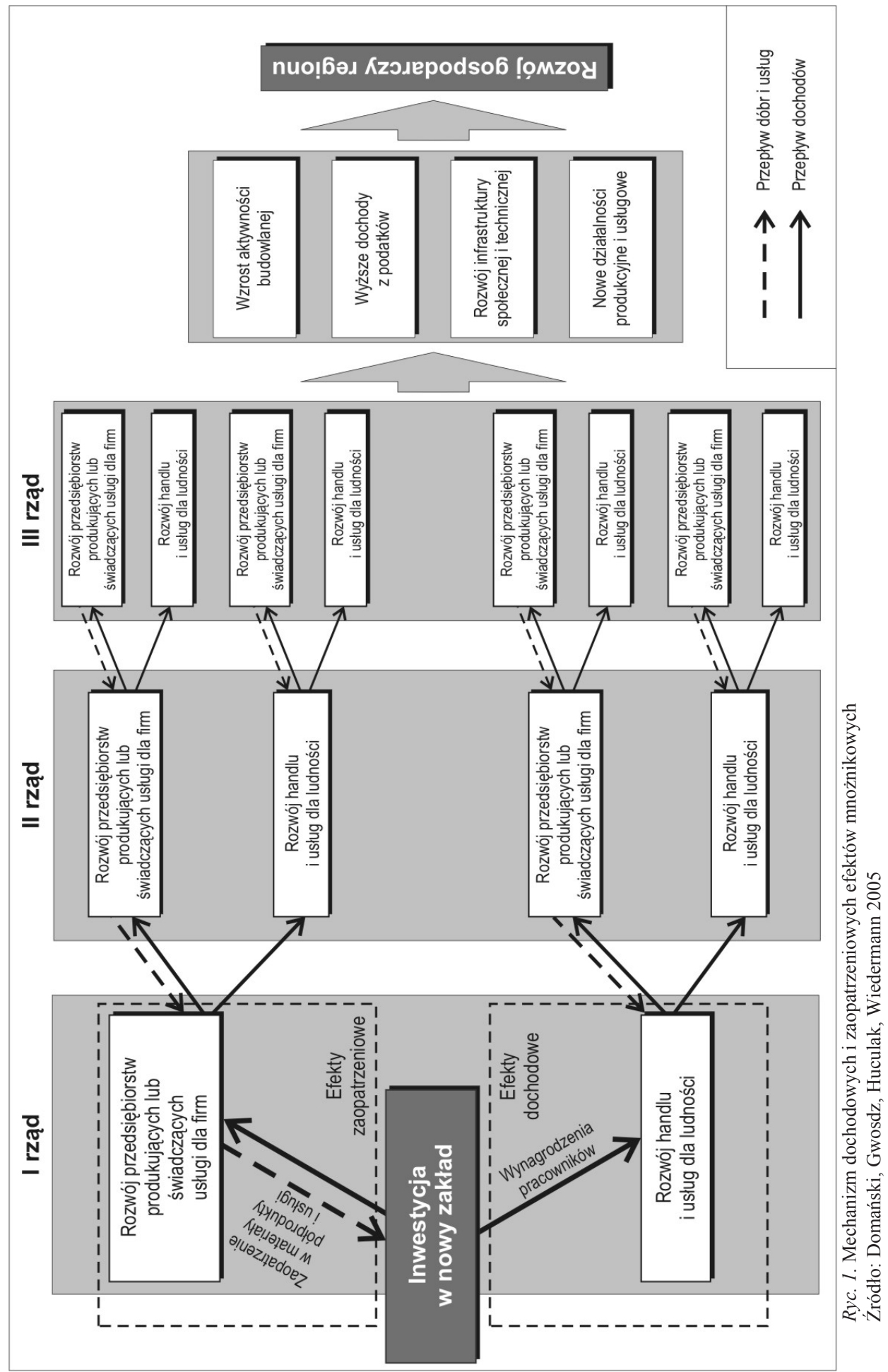


nów, których autorami byli m.in. W. Lee Hansen i Ch.M. Tiebout (1963), K. Sasaki (1963), S.J. Weiss i E. Gooding (1968), P. Bourque (1969), D.H. Garnick (1970), N.J. Glickman (1971), P. Lloyd i P. Dicken (1972), J.M. Mattila (1973), O.P. Hall i J.A. Licari (1974), R.L. Drake (1976). Z nowszej literatury należy wymienić prace następujących autorów: R. Hayter i H.D. Watts (1983), A.J. Scott (1988), S.M. Brucker, S.E. Hastings, W.R. Latham (1990), S. Conti (1993), P. Dicken, M. Forsgreen i A. Malmberg (1994) oraz opracowanie zbiorowe pod redakcją S. Contiego, E.J. Maleckiego i P. Oinas (1995). W polskiej literaturze geograficznej w ostatnim czasie powstało kilka opracowań na temat oddziaływania przedsiębiorstw przemysłowych na otoczenie lokalne i regionalne. Należą do nich praca B. Domańskiego (2004), opracowanie pod redakcją T. Stryjakiewicza (2004) na temat wpływu firmy inwestorów zagranicznych na otoczenie na przykładzie firmy GlaxoSmithKline oraz praca pod redakcją B. Domańskiego i K. Gwosdza (2005) dotycząca wpływu przedsiębiorstw zlokalizowanych w mieleckiej SSE na region mielecki.

Wielokrotnie przedmiotem badań była siła powiązań nowych dużych inwestorów zagranicznych z ich otoczeniem w krajach Europy Środkowej i Wschodniej. Często wynikiem tych badań był pogląd, że zakorzenienie (embeddedness) lokalne tego typu inwestorów jest niewielkie. Została nawet w tym kontekście użyta metafora „katedr na pustyni” (Grabher 1994), mająca wyrażać słabe osadzenie nowych inwestycji przemysłowych w otoczeniu lokalnym i regionalnym wschodnich Niemiec, a tym samym ich niewielki wpływ na szerszy rozwój gospodarczy. Charakter izolowanej enklawy pozbawionej istotnych powiązań z otoczeniem lokalnym, regionalnym, a nawet krajowym przypisywany jest również niektórym inwestycjom w Polsce (np. Hardy 1998). Szersze badania nad funkcjonowaniem inwestorów zagranicznych w Polsce pokazują jednak znacznie bardziej złożony obraz ich relacji z otoczeniem, w tym powiązań usługowych i oddziaływania za pośrednictwem kadry i jej dochodów (Domański 2001, 2004; Domański, Gwosdz 2005; Sobala-Gwosdz 2000; Stryjakiewicz 2004).

Istotne znaczenie mają wielkość i przestrzenny rozkład efektów mnożnikowych. Na efekty te składa się rozwój zarówno lokalnych przedsiębiorstw, jak i dostawców zlokalizowanych w innych obszarach. Im więcej materiałów i usług nabywane jest przez firmy na rynku lokalnym, tym większe jest regionalne „domknięcie” efektów mnożnikowych.

Od czego zależy wielkość efektów mnożnikowych? Przede wszystkim od rodzaju działalności gospodarczej oraz rozmiarów i cech przedsiębiorstwa. Poszczególne działalności (branże) oraz firmy różnią się również przestrzennym zasięgiem efektów mnożnikowych, w tym stopniem ich lokalnego domknięcia. Lokalne efekty zaopatrzeniowe są zazwyczaj silniejsze w przypadku firm dłużej działających w danym miejscu, przedsiębiorstw z kapitałem rodzimym, w tym zwłaszcza mających w danym miejscu swą siedzibę. Natomiast dla firm zagranicznych, szczególnie nowych fabryk, zorientowanych na rynki zagraniczne są one nierzadko słabsze (Domański 2001). Lokalne efekty mnożnikowe powstające poprzez zlecanie usług są najczęściej silniejsze niż efekty wynikające z zaopatrzenia produkcyjnego. Najbardziej lokalny charakter mają z natury rzeczy dochodowe efekty mnożnikowe związane z miejscem zamieszkania pracowników, ponieważ ich wielkość ma ścisły związek $\mathrm{z}$ liczbą miejsc pracy oraz poziomem wynagrodzeń w firmach.

Cechy społeczne i gospodarcze danego obszaru mają duży wpływ na wielkość lokalnych efektów mnożnikowych - przechwytywanie przez miasto i jego otoczenie efektów mnożnikowych jest w niemałym stopniu wynikiem zdolności miejscowych firm do zaspokajania popytu zgłaszanego przez nowych inwestorów. Uzależnione jest to od wielkości, 
poziomu rozwoju i struktury gospodarki lokalnej oraz aktywności miejscowych podmiotów gospodarczych, a częściowo także władz publicznych.

Przedmiotem tego opracowania jest operacjonalizacja metody szacowania wielkości efektów mnożnikowych, które generowane są przez przedsiębiorstwa przemysłowe zlokalizowane na określonym terenie, oraz ocena ich „domknięcia” w skali lokalnej i regionalnej. W pierwszej kolejności analizowane są efekty mnożnikowe powstające za pośrednictwem zaopatrzenia firm w strefie w materiały, półprodukty i części do produkcji, a następnie efekty związane ze zlecaniem przez nie różnorodnych usług. Szeroko potraktowano oddziaływanie strefy na rozwój miejscowych firm poprzez dochody zatrudnionych tam pracowników.

\section{METODA OBLICZANIA EFEKTÓW MNOŻNIKOWYCH}

Wielkość efektów mnożnikowych jest wyznaczana zawsze dla określonego przedziału czasu. Jeżeli pomiędzy dwoma przekrojami czasowymi wyznaczającymi daną jednostkę nastąpił rozwój określonych przedsiębiorstw tak, że wygenerowały one dodatkowy popyt konsumpcyjny bądź zaopatrzeniowy, efekty mnożnikowe są korzystne dla danej gospodarki, gdyż dzięki nim powstają na danym obszarze nowe miejsca pracy. Do obliczenia ilości miejsc pracy powstałych dzięki funkcjonowaniu przedsiębiorstw przemysłowych poprzez proces efektów mnożnikowych konieczne jest zatem wyznaczenie okresu czasu, dla którego będziemy te efekty obliczać.

W przyjętej metodzie wielkość efektów mnożnikowych wyraża się liczbą osób zatrudnionych poza nowo powstałymi inwestycjami, których praca jest wynikiem funkcjonowania tych firm. Podstawę obliczenia efektów mnożnikowych stanowią informacje pozyskane drogą ankiet i wywiadów przeprowadzonych na reprezentatywnej grupie przedsiębiorstw przemysłowych oraz w podmiotach gospodarczych, które są ich kooperantami. Część informacji na temat kosztów działalności, średnich płac czy koszyka wydatków gospodarstw domowych jest możliwa do pozyskania ze statystyki publicznej (GUS) i sprawozdań finansowych przedsiębiorstw (Monitor Polski B). W przypadku rozbieżności danych pochodzących z kilku źródeł przyjmowano niższe wartości, co oznacza, że wyliczona wielkość zatrudnienia może być raczej niedoszacowana niż przeszacowana. Dzięki temu możemy stwierdzić, jaka minimalna liczba miejsc pracy została utworzona dzięki nowym inwestycjom.

Ze względu na zróżnicowaną metodę obliczania miejsc pracy będących wynikiem dochodowych i zaopatrzeniowych efektów mnożnikowych, sposobowi ich wyznaczania poświęcono dwie odrębne części tego artykułu.

\section{ZAOPATRZENIOWE EFEKTY MNOŻNIKOWE}

Do zaopatrzeniowych efektów mnożnikowych należy dostawa surowców i materiałów produkcyjnych (zaopatrzeniowe produkcyjne efekty mnożnikowe) oraz świadczenie usług na rzecz przedsiębiorstwa (zaopatrzeniowe usługowe efekty mnożnikowe).

W zakresie zaopatrzeniowych efektów mnożnikowych wyznaczono grupę usług, z których potencjalnie mogą korzystać przedsiębiorstwa. Należą do nich następujące rodzaje usług świadczonych na rzecz firm: 
- usługi transportowe,

- sprzątanie i utrzymanie ruchu,

- wykonywanie narzędzi i serwisowanie urządzeń,

- ochrona,

- usługi w zakresie projektowania i prace badawcze,

- usługi prawne,

- usługi finansowe,

- usługi informatyczne,

- usługi w zakresie szkolenia pracowników.

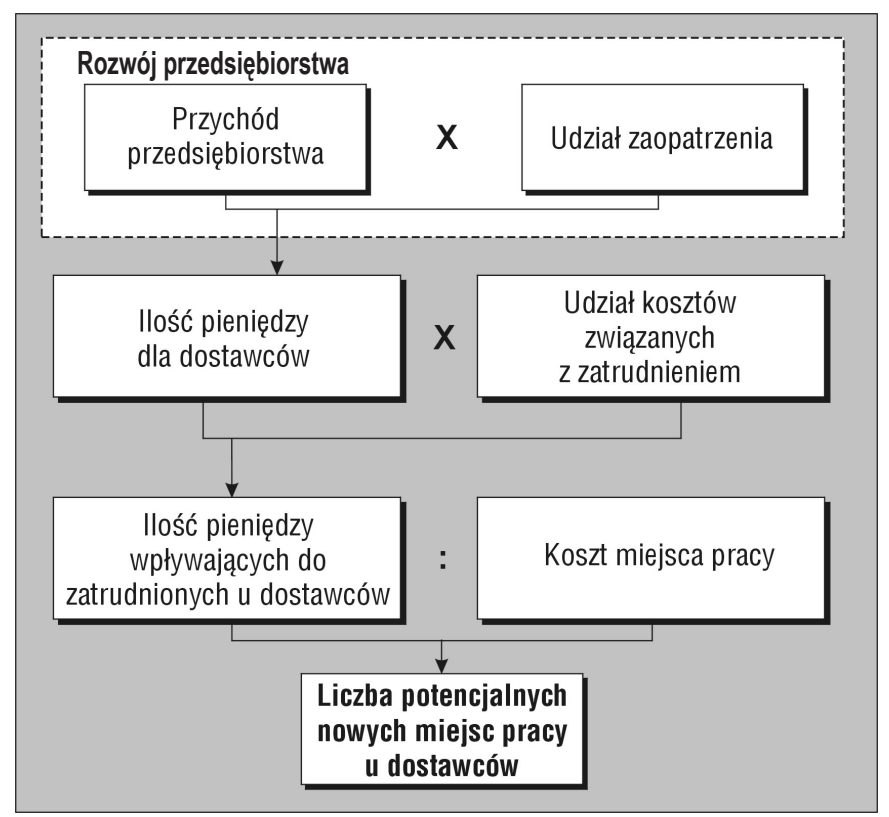

Ryc. 2. Algorytm obliczania zaopatrzeniowych efektów mnożnikowych

Źródło: Opracowanie własne

W celu wyznaczenia wielkości oraz zasięgu oddziaływania określonego rodzaju inwestycji na otoczenie $\mathrm{w}$ trakcie wywiadów $\mathrm{w}$ reprezentatywnie dobranej grupie firm należy pozyskać informacje na temat korzystania z powyższych rodzajów usług w zakresie miejsca pochodzenia kontrahentów oraz ilości osób, które są zaangażowane w pracy na rzecz poszczególnych firm.

Na podstawie tak przeprowadzonych rozmów, a także wywiadów z kooperantami działającymi w poszczególnych branżach zgodnie $\mathrm{z}$ opracowanym algorytmem przedstawionym na wyżej zamieszczonym schemacie (ryc. 2) można oszacować wielkość zatrudnienia generowanego u dostawców, w tym celu bowiem konieczne jest posiadanie danych na temat przychodu przedsiębiorstw, udziału zaopatrzenia w przychodzie i kosztów związanych z zatrudnieniem.

W przypadku gdy nie dysponujemy danymi na temat przychodów poszczególnych firm czy też całych grup przedsiębiorstw, istnieje konieczność ich wyliczenia. W tym przypadku obliczenia można dokonać na podstawie liczby miejsc pracy istniejących w danych firmach czy branżach oraz struktur kosztów pracy w przychodach i koszcie jednego miejsca pracy dla danego rodzaju działalności (ryc. 3). 


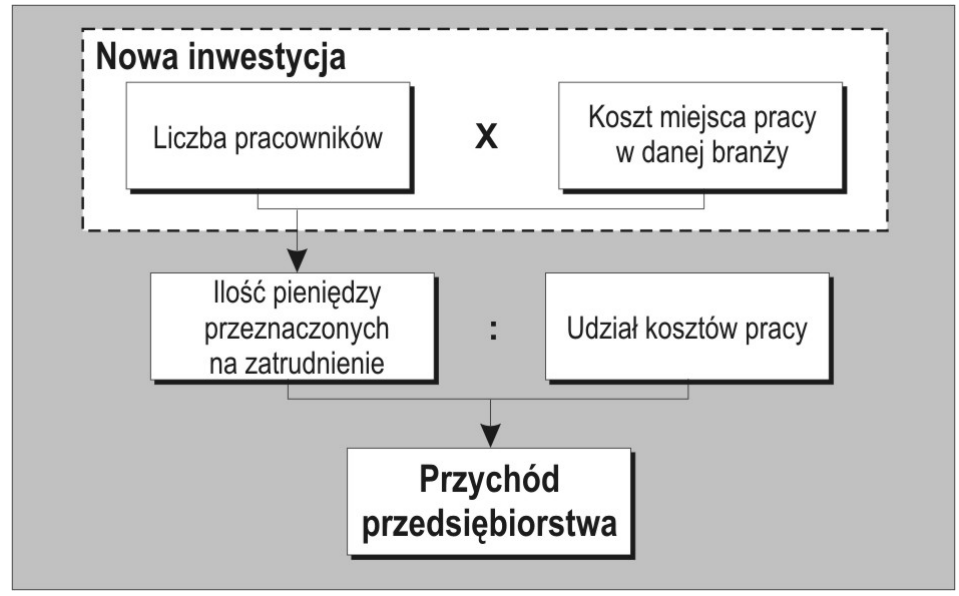

Ryc. 3. Algorytm obliczania przychodu przedsiębiorstw

Źródło: Opracowanie własne

Po obliczeniu liczby miejsc pracy generowanych w zaopatrzeniu przedsiębiorstw w kolejnych rzędach efektów mnożnikowych należy dokonać zsumowania otrzymanych wyników. Wartość ta stanowi łączną oszacowaną liczbę miejsc pracy powstałych dzięki zaopatrzeniowemu popytowi generowanemu poprzez nowe inwestycje.

\section{DOCHODOWE EFEKTY MNOŻNIKOWE}

Mnożnikowe efekty dochodowe są skutkiem zwiększenia się siły nabywczej ludności poprzez wynagrodzenia pracowników, co prowadzi do rozwoju firm zaspokajających potrzeby konsumpcyjne. Im więcej ludzi ma pracę na skutek powstania nowych działalności lub rozwoju istniejących i im więcej ludzie ci zarabiają, tym większe są dochodowe efekty mnożnikowe powstałe $\mathrm{w}$ wyniku popytu konsumpcyjnego. W opracowaniu zamieszczono schemat (ryc. 4) pozwalający obliczyć liczbę nowych miejsc pracy powstałych na skutek nowych inwestycji.

Jeżeli w wyniku nowej inwestycji powstają miejsca pracy, to ich pomnożenie przez płace netto da sumę pieniędzy przeznaczanych przez daną grupę pracowników na cele konsumpcyjne. Otrzymany w ten sposób iloczyn mnożymy przez udział poszczególnych branż w koszyku wydatków, który jest publikowany przez GUS, w wyniku czego otrzymujemy przychód pieniądza do poszczególnych branż. Po pomnożeniu tej wartości przez udział kosztów pracy dla danej branży, a następnie po podzieleniu jej przez koszt miejsca pracy otrzymujemy liczbę nowo utworzonych miejsc pracy w określonym rodzaju działalności. Suma miejsc pracy dla wszystkich branż daje łączną ilość miejsc pracy utworzonych dzięki popytowi konsumpcyjnemu pracowników przedsiębiorstw przemysłu motoryzacyjnego. Kolejny rząd efektów mnożnikowych stanowi natomiast popyt konsumpcyjny generowany przez pracowników przedsiębiorstw poszczególnych branż, w których powstały nowe miejsca pracy. Dla tych miejsc pracy obliczamy kolejny rząd efektów mnożnikowych zgodnie $\mathrm{z}$ tą samą procedurą (ryc. 4). 


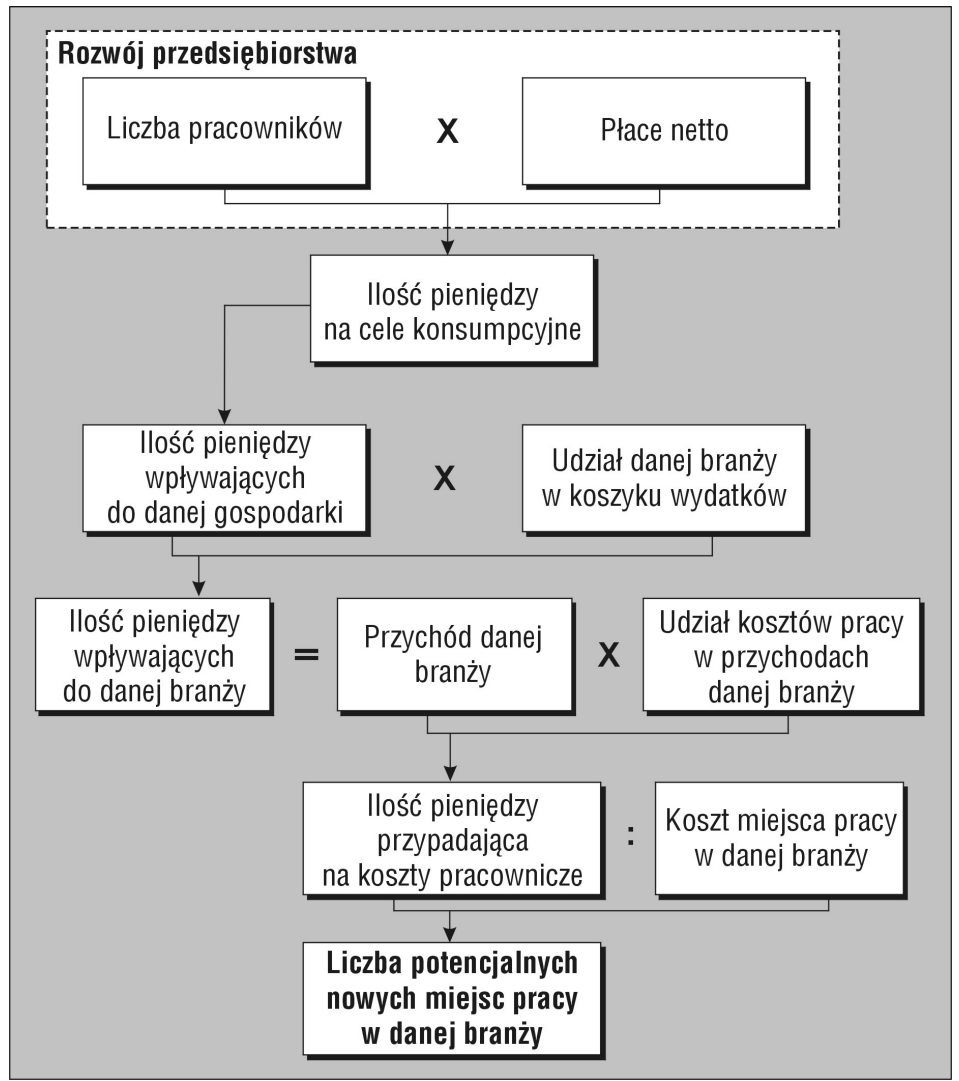

Ryc. 4. Algorytm obliczania dochodowych efektów mnożnikowych

Źródło: Opracowanie własne

\section{Podsumowanie}

Wnioski w zakresie teoretyczno-metodycznym stanowią pochodne opracowanej metody obliczania miejsc pracy generowanych poprzez efekty mnożnikowe. Metoda ta może mieć wartość aplikacyjną dla opracowań dotyczących rozwoju lokalnego i regionalnego. Można za jej pomocą oszacować powstające w wyniku nowej inwestycji miejsca pracy w danej gospodarce i na tej podstawie określić np. pomoc dla danego przedsiębiorstwa m.in. poprzez ulgi inwestycyjne, tak aby było to opłacalne dla regionu. Poza tym może ona służyć także przedsiębiorcom do wykazywania nisz rynkowych w działalnościach endogenicznych. W przypadku gdy znamy wielkość środków finansowych wpływających do danej gospodarki, możemy wyliczyć ilość miejsc pracy w poszczególnych działalnościach endogenicznych. Po porównaniu z danymi o faktycznych miejscach pracy możemy ustalić, czy na danym rynku jest nadmiar czy niedostatek podmiotów w określonych działalnościach. 
Opracowana metoda wyznaczania wielkości efektów mnożnikowych, podobnie jak wiele innych, ma swoje ograniczenia w zakresie dokładności obliczanego wyniku. Jest to spowodowane koniecznością przyjęcia szacunkowych danych początkowych. Błąd przy podawaniu danych w zakresie struktury kosztów pracy i kosztu miejsca pracy w poszczególnych działalnościach jest niewielki. Przy dużej liczbie przedsiębiorstw odchylenia od średniej wartości dla poszczególnych rodzajów działalności są niewielkie, a do tego waga tych składowych nie ma aż tak dużego wpływu na wynik końcowy. Większy błąd oszacowania pojawić się może w przypadku obliczeń domknięcia lokalnego lub regionalnego. Szczególnie w przypadku rozpatrywanej nowej inwestycji błąd wynikający z określenia obszaru domknięcia zaopatrzeniowego firmy czy też potencjalnych dojazdów do pracy może być duży. O dokładniejsze szacowanie tego typu jest łatwiej w przypadku ośrodków izolowanych, gdzie domknięcie chociażby rynku pracy jest bardziej naturalne.

\section{Literatura}

Bourque P. 1969, Income Multipliers for the Washington Economy, University of Washington, Center for Urban and Regional Research

Brucker S.M., Hastings S.E., Latham W.R. 1990, The Variation of Estimated Impacts from Five Regional Input-Output Models, „International Regional Science Review”, 13, 119-39

Conti S., 1993, The network perspective in industrial geography. Towards a model, „Geogr. Annaler”, $75 \mathrm{~B}, 3,115-130$

Conti S., Malecki E.J., Oinas P. (eds), 1995, The industrial enterprise and its environment, Aldershot, Avebury

Dicken P., Forsgreen M., Malmberg A. 1994, Local embeddedness and transnational corporations [in:] Globalisation, institutions and regional development in Europe, eds. A. Amin, N. Thrift, Oxford Univ. Press, Oxford, 23-45

Domański B. 2001, Kapital zagraniczny w przemyśle Polski, Instytut Geografii i Gospodarki Przestrzennej UJ, Kraków

Domański B. 2004, Local and regional embeddedness of foreign industrial investors in Poland, Prace Geograficzne, Instytut Geografii i Gospodarki Przestrzennej UJ, Kraków

Domański B., Gwosdz K. (red.), 2005, Dziesięć lat doświadczeń pierwszej polskiej specjalnej strefy ekonomicznej. Mielec 1995-2005, UJ, Instytut Geografii i Gospodarki Przestrzennej, ARP o. Mielec, Kraków

Domański B., Gwosdz K., Huculak M., Wiedermann K. 2005, Oddziaływanie SSE Euro-Park Mielec na otoczenie lokalne. Powiqzania firm i efekty mnożnikowe, [w:] Dziesięć lat doświadczeń pierwszej polskiej specjalnej strefy ekonomicznej Mielec 1995-2005, Instytut Geografii i Gospodarki Przestrzennej UJ, ARP o. Mielec, Kraków

Drake R.L. 1976, A Short-Cut to Estimates of Regional Input-Output Multipliers, „International Regional Science Review" 1, 1-17

Garnick D.H. 1970, Differential Regional Multiplier Models, „Journal of Regional Science”, 10, $35-47$

Glickman N.J. 1971, An Econometric Forecasting Model for the Philadelphia Region, „Journal of Regional Science", 11, 15-32

Grabher G. 1994, The disembedded regional economy: the transformation of East German industrial complexes into western enclaves, [in:] Globalization, institutions and regional development in Europe, eds. A. Amin, N. Thrift, Oxford Univ. Press, Oxford, 177-195

Hall O.P., Licari J.A. 1974, Building Small Region Econometric Models: Extension of Glickman's Structure to Los Angeles, „Journal of Regional Science”, 14, 337-353 
Hardy J. 1998, Cathedrals in the desert? Transnationals, corporate strategy and locality in Wroctaw, „Reg. Stud.”, 32, 7, 639-652

Hayter R., Watts H.D. 1983, The geography of enterprise: a reappraisal, „Progress in Human Geogr.”, 7, 157-181

Lee Hansen W., Tiebout Ch.M. 1963, An Intersectoral Flows Analysis of the California Economy, „The Review of Economics and Statistics", 45, 409-419

Lloyd P., Dicken P. 1972, Location in space: a theoretical approach to economic geography, Harper\&Row, New York, San Francisco, London

Mattila J.M. 1973, A Metropolitan Income Determination Model and the Estimation of Metropolitan Income Multipliers, ,Journal of Regional Science”, 13, 1-16

Myrdal G. 1957, Economic Theory and Under-Developed Regions, Duckworth, London

Sasaki K. 1963, Military Expenditures and the Employment Multiplier in Hawaii, „The Review of Economics and Statistics", 45, 289-304

Scott A.J. 1988, New industrial space: flexible production and regional economic development in the USA and Western Europe, Pion, London

Sobala-Gwosdz A. 2000, The influence of large manufacturing firmson the local development of Jarostaw in the 1990s, [w:] Local economy and urban development of Poland, red. T. Marszał, Wydawnictwo Uniwersytetu Łódzkiego, Łódź, 62-69

Stryjakiewicz T. red., 2004, Wplyw inwestorów zagranicznych na rozwój regionalny i lokalny, Bogucki, Wyd. Naukowe, Poznań

Tiebout Ch.M. 1957, Interregional Input-Output Models: An Appraisal, „Southern Economic Journal”, 24, 140-147

Weiss S.J., Gooding E. 1968, Estimation of Differential Employment Multipliers in a Small Regional Economy, „Land Economics”, 44, 235-244

\section{The concept of multiplier effect in determining the influence of enterprises on their socio-economic environment}

The subject of this paper is presentation of a method of calculating multiplier effects in order to determine the influence of enterprises on their environment. Emergence or development of economic activity in a given area may bring about an increase in income and employment in many other enterprises, as well as to an increase taxes collected by the local authority. This increase is labelled multiplier effects, and its value enables the evaluation of the enterprise's activity on the functioning of neighbouring firms.

In literature, the most frequently discussed types of multiplier effects are the supply and income effects. The first result from the demand created by the emerging and developing enterprises, which fosters the development of their goods and services suppliers. The second type, the income effects, result from the increase in purchasing power of the inhabitants, owing to the employees' remuneration, and this means fostering the development of firms that satisfy consumers' needs. These enterprises create greater demand themselves, thus triggering new cycles of multiplier effects.

The calculation of created workplaces for the supply effects was conducted by using a designed algorithm. It allows calculating the new workplaces in the supplier firms on the bases of data concerning income of enterprises, participation of supply in the revenue, and employment-related costs. The growth of employment and payment is correlated with the increase in the income multiplier effects, generated by single enterprises. This work presents a scheme for calculation of new workplaces created as a result of new investments. 